\section{An end to patronage?}

\section{London}

THE East German Academy of Sciences last week issued a statement calling for appointments to management posts in science, education, the health service and the economy to be made on merit, not by Party allegiance. In what amounts to a rejection of the nomenklatura system, the Presidium of the Academy declared that posts should be filled according to the professional competence, leadership qualities, moral integrity and "solidarity with socialism" of the candidate. The meaning of this last phrase was not made entirely clear, but the term was explicitly contrasted with "Party membership", whose value as a "decisive criterion" was rejected. Moreover, the Academy said, all elective posts in these fields should be made by secret ballot, and from a genuine choice of candidates.

The Presidium statement maintained that, in the past, political decision makers had largely ignored the research results and expert

studies produced by Acad- East Germany's exodus continues: jubilant refugees, mainly emy scholars. Scientists, it Trabant drivers, arrive in Schirnding in the West. (AP).

said, have a decisive role to play in the "spiritual and material renewal" of East Germany, and a fresh strategy for science must therefore form part of the muchneeded reform programme; there should be a transition to "nonbureaucratic" forms of planning which would promote initiative. To give science the status it deserves, the Academy proposed that a special the General Committee of the Socialist Unity Party. On the other hand, it declared its support for "new social solutions, and the open debate of opinions".

Reasoned scientific analysis, the drawing up of expert opinions, and "responsible disciplined work" are the Academy's prescription for the ills of East Germany.

Vera Rich HUNGARIAN SCIENCE

\section{Pay rise move to stem brain drain}

\section{London}

IN an attempt to halt Hungary's braindrain, Prime Minister Miklos Nemeth has promised the country's 25,000 research workers in science, education and health a pay raise of 16 per cent over and above the rate of inflation. Since the beginning of this year, up to ten scientists a day have been leaving the country to take up research posts abroad. The latest figures indicate that some 12 per cent of Hungary's scientists take posts abroad each year, and one quarter of these stay away for more than five years, or take up permanent residence in the West.

Professional frustration is as much a cause as low salaries. Many scientists find it impossible to do their experimental work in Hungary, and hence ask their foreign colleagues for short-term invitations to work abroad.

Hungary's lack of Western currency makes it difficult to buy advanced labora- tory equipment, but the main problem is the way in which science is financed. For decades, the Hungarian budget has been divided up according to the "residual principle" of old-style Marxism: "non-productive" activities - science, education, and health - were given what remained in the coffers after all other expenses had been met.

During 1987 and 1988, and particularly after the establishment of the independent Democratic Trade Union of Scientific Workers (TUDDOSZ) in April 1988, Hungarian scientists became increasingly a letter to the Hungarian Academy of Sciences announcing the pay rise, Premier Nemeth has now promised that the residual principle would be replaced by a system in which the allocation of funding to science, education and health will reflect the importance of these areas.

Vera Rich vocal in their criticism of this principle. In

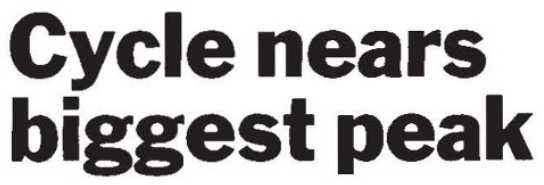

\section{Washington}

As solar activity increases towards a projected 11-year maximum in February next year, the peak of the current solar cycle is on a course to challenge the 1958 maximum as the biggest on record. Already, two solar flares of unprecedented magnitude have occurred this year, disrupting radio communications and in one case setting off safety cut-outs in the electricity supply grid in Quebec and triggering a blackout over most of the province.

Solar activity is conventionally measured by the number of sunspots, and for cycle 22, now approaching its peak, the number is running level with the record of cycle 19 , which peaked about 33 years ago. But because the 11-year periodicity in the solar cycle is only approximate, whether cycle 22 exceeds cycle 19 will depend on whether the sunspot number keeps on rising as projected or begins to decline a little earlier than expected. In terms of terrestrial disturbances, the sunspot number is in any case somewhat academic; what causes trouble is magnetic activity, including solar flares, which tends to peak a year or two after the sunspot maximum and whose severity is imperfectly correlated with the sunspot number.

The two large flares this year, one occurring in March and the other last week, were both of a size and intensity that Joe Allen, director of solar-terrestrial physics for the National Oceanic and Atmosphere Administration (NOAA) in Boulder, Colorado, said he had not previously seen. The flares produced intense X-ray emission, measured by NOAA satellites, and more unusually had been observed in in ground-based neutron and proton detectors.

One indication of the severity of this year's events, according to Allen, was that it was becoming increasingly difficult to track the thousands of mostly unidentified objects orbiting the Earth. Magnetic disturbances propagating from the Sun cause local electromagnetic disturbances which heat the atmosphere by generating currents. The visible consequence is more aurorae - there have been reports from as far south as the Mexican border - but for orbiting bodies the important effect is that the heated atmosphere expands away from the Earth a little, increasing frictional drag. Typically, in the tens of thousands of orbits tracked by the US Department of Defense, about a thousand every day change enough to make identification with a previous orbit impossible. But soon after the giant solar flares, said Allen, the number of lost orbits went up to 6,000 a day.

David Lindley 